\title{
Justification of VVER-1000 safety when using fuel compositions doped by protactinium and neptunium ${ }^{*}$
}

\author{
Tuul Baatar ${ }^{1}$, Evgeny G. Kulikov ${ }^{1}$ \\ 1 National Research Nuclear University MEPhI, 31 Kashirskoe Shosse, Moscow 115409, Russia \\ Corresponding author: Evgeny G. Kulikov (egkulikov@mephi.ru)
}

Academic editor: Yury Korovin • Received 15 March 2019 • Accepted 7 May 2020 • Published 25 June 2020

Citation: Baatar T, Kulikov EG (2020) Justification of VVER-1000 safety when using fuel compositions doped by protactinium and neptunium. Nuclear Energy and Technology 6(2): 99-104. https://doi.org/10.3897/nucet.6.55218

\begin{abstract}
Increasing fuel burnup is one of the important areas of nuclear power development. Currently, the most common type of light-water reactors is characterized by burnup ratios of about $5 \%$, i.e., only a small fraction of fuel is used to generate electricity. The paper considers the possibility of a significant increase in fuel burnup due by introducing protactinium and neptunium into the fuel composition. The chains of nuclide transformations starting with protactinium and neptunium are characterized by a gradual improvement in the multiplying properties, which ensures increased fuel burnup. At the same time, a situation may be observed when the multiplying properties of a fuel composition are improved during the campaign, which indicates that at a certain point in time the accumulation rate of fissile nuclides from protactinium and neptunium exceeds the accumulation rate of fission products. While protactinium is hardly accessible in sufficient quantities, neptunium is contained in spent nuclear fuel, a significant amount of which is stored in on-site facilities. Therefore, from a practical perspective, the introduction of neptunium into fuel compositions seems to be more preferable. The novelty of the work is the analysis of the effects of protactinium and neptunium on the reactivity coefficients during fuel campaigns. The calculations were carried out for a VVER-1000 type reactor using the SCALE-6.2 software package.
\end{abstract}

\section{Keywords}

Ultra-high fuel burnup, light-water reactor, protactinium, neptunium, fuel temperature coefficient of reactivity, coolant temperature coefficient of reactivity

\section{Introduction}

Modern light-water reactors have fuel burnup ratios of about $5 \%$. Thanks to new fuel technologies and, in particular, to the use of advanced burnup absorbers, it is possible to achieve $6 \%$ burnup.

Increasing fuel burnup is necessary to:

- improve the economy of the nuclear fuel cycle by reducing the volume of fresh and spent nuclear fuel;
- reduce the number of fuel reloads; and

- reduce the likelihood of switching fissile material from spent fuel to non-energy targets (Klimov 1985).

\section{Initial data}

To increase fuel burnup, we shall consider the possibility of introducing protactinium and neptunium into fuel com-

* Russian text published: Izvestiya vuzov. Yadernaya Energetika (ISSN 0204-3327), 2020, n. 1, pp. $26-36$.

Copyright Baatar T, Kulikov EG. This is an open access article distributed under the terms of the Creative Commons Attribution License (CC-BY 4.0), which permits unrestricted use, distribution, and reproduction in any medium, provided the original author and source are credited. 
positions. This issue was previously studied in (Kulikov et al. 2013; Shmelev et al. 2016), but the effects of these nuclides on the reactivity coefficients during fuel campaigns has not been adequately investigated so far. Note that the problem of achieving ultra-high burnup is considered only in terms of choosing a fuel composition while the material science aspect is not analyzed. It should also be noted that, in the experimental fuel elements at the BOR-60 reactor, burnup of more than $30 \%$ was achieved with vibropac MOX-fuel (Maershin et al. 2001).

We consider the unit cell of a VVER-1000 reactor: its parameters are presented in Table 1.

Table 1. VVER-100 unit cell parameters (Subrata 2008).

\begin{tabular}{lc}
\hline \multicolumn{1}{c}{ Parameter } & Value \\
\hline Fuel density, $\mathrm{g} / \mathrm{cm}^{3}$ & 10.7 \\
Fuel inner/outer radius, cm & $0.115 / 0.375$ \\
FE cladding inner/outer radius, cm & $0.386 / 0.4582$ \\
Cladding/central tube material & $\mathrm{Zr}(1 \% \mathrm{Nb}, 0.03 \% \mathrm{Hf})$ \\
Cladding density, $\mathrm{g} / \mathrm{cm}^{3}$ & 6.45 \\
Central tube inner/outer radius, cm & $0.45 / 0.515$ \\
FE array pitch, cm & 1.275 \\
Moderator density, g/ $\mathrm{cm}^{3}$ & 0.71 \\
Fuel temperature, $\mathrm{K}$ & 966 \\
Cladding temperature, $\mathrm{K}$ & 630 \\
Moderator temperature, $\mathrm{K}$ & 578 \\
\hline
\end{tabular}

All the subsequent burnup-related calculations are made for an equivalent cell by means of the SCALE- 6.2 software package, a widely used set of modeling and simulation tools for performing neutron-physical calculations (SCALE, Gauld et al. 2011, Bowman 2007, Rearden and Jessee 2016).

As a result of radiative neutron capture reactions on protactinium and neptunium, moderately fissile isotopes of uranium-232 and plutonium-238 are accumulated, leading to the accumulation of well-fissile isotopes of uranium-233 and plutonium-239 (Table 2). Thus, the neutron-multiplying properties of such fuel compositions are improved during a campaign, thereby ensuring higher fuel burnup.

\section{Introducing neptunium into fuel compositions}

According to its neutron-physical properties, ${ }^{237} \mathrm{~Np}$ is a raw nuclide. Neptunium has large capture cross-sections

Table 2. Neutron fission/capture cross-sections at a heat spot and the number of neutrons per fission event (Babichev et al. 1991; Maslov et al. 2004; Shibata et al. 2011; Soppera et al. 2014).

\begin{tabular}{lcccc}
\hline \multirow{2}{*}{ Nuclides } & \multicolumn{2}{c}{ Cross-section, barn $\left(\mathbf{E}_{\mathbf{n}}=\mathbf{0 . 0 2 5 3} \mathbf{~ e V}\right)$} & $\boldsymbol{v}_{\mathbf{f}}$ \\
\cline { 2 - 4 } & & $\boldsymbol{\sigma}_{\mathbf{f}}$ & $\boldsymbol{\sigma}_{\mathbf{c}}$ & \\
\hline Fertile & ${ }^{238} \mathrm{U}$ & $1.7 \times 10^{-5}$ & 2.7 & 2.32 \\
& ${ }^{232} \mathrm{Th}$ & $5.4 \times 10^{-5}$ & 7.3 & 1.89 \\
& ${ }^{231} \mathrm{~Pa}$ & 0.023 & 202 & 2.09 \\
\multirow{5}{*}{ Fissile } & ${ }^{237} \mathrm{~Np}$ & 0.020 & 178 & 2.62 \\
& ${ }^{233} \mathrm{U}$ & 531 & 45 & 2.48 \\
& ${ }^{235} \mathrm{U}$ & 585 & 99 & 2.43 \\
& ${ }^{239} \mathrm{Pu}$ & 747 & 271 & 2.87 \\
& ${ }^{232} \mathrm{U}$ & 77 & 75 & 3.12 \\
\hline
\end{tabular}

in both the thermal and resonance regions. The thermal neutron-capture cross-section of ${ }^{237} \mathrm{~Np}$ is 178 barn, and the fission cross-section is 0.020 barn (see Table 2). This means that ${ }^{237} \mathrm{~Np}$ practically does not split into thermal and intermediate neutrons, but as a result of the capture reaction on neptunium and subsequent $\beta$-decay, moderately fissile ${ }^{238} \mathrm{Pu}$ is accumulated, leading to the accumulation of well-fissile ${ }^{239} \mathrm{Pu}$ (Fig. 1).

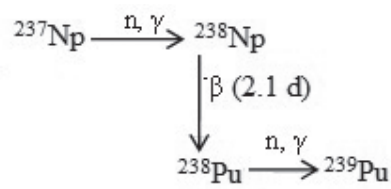

Figure 1. A chain of nuclide transformations starting with neptunium (Bowman 2007).

Figure 2 shows the neutron multiplication factor in the process of burning fuel containing neptunium.

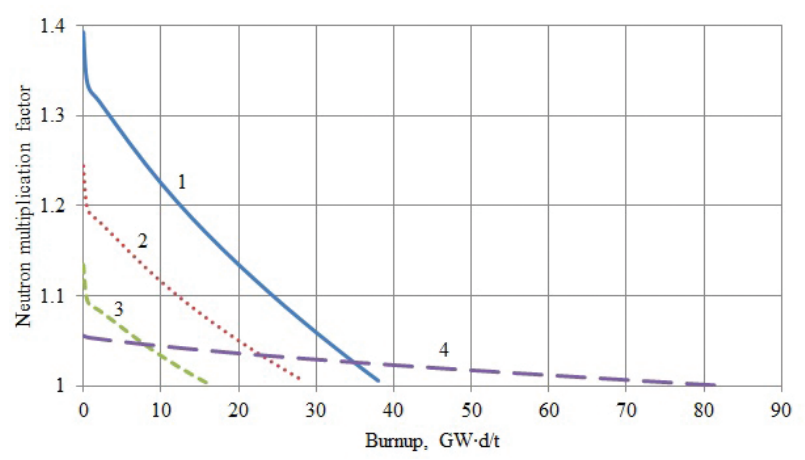

Figure 2. The effect of neptunium on the neutron multiplication factor in the process of fuel burnup: 1) conventional uranium fuel $\left(4.4 \%\right.$ of ${ }^{235} U+95.6 \%$ of $\left.\left.{ }^{238} U\right) ; 2\right)$ introducing $1 \%$ of neptunium $\left(4.4 \%\right.$ of ${ }^{235} U+94.6 \%$ of ${ }^{238} U+1 \%$ of $\left.\left.{ }^{237} \mathrm{~Np}\right) ; 3\right)$ introducing $2 \%$ of neptunium $\left(4.4 \%\right.$ of ${ }^{235} U+93.6 \%$ of ${ }^{238} U+2 \%$ of $\left.{ }^{237} \mathrm{~Np}\right) ; 4$ ) introducing a large amount of neptunium (35\% of ${ }^{235} \mathrm{U}+65 \%$ of ${ }^{237} \mathrm{~Np}$ ).

With a small addition of ${ }^{237} \mathrm{~Np}$ (the second and third fuel compositions), the initial neutron multiplication factor decreases relative to conventional uranium fuel, and achievable burnup is small, which indicates that the accumulation potential of fissile plutonium isotopes does not have time to be realized. At the same time, in the case of using a fuel composition containing $35 \%$ of ${ }^{237} \mathrm{~Np}$ instead of $35 \%$ of ${ }^{238} \mathrm{U}$, burnup reaches $82 \mathrm{GW} \cdot \mathrm{d} / \mathrm{t}$ and the neutron multiplication factor remains close to unity throughout the campaign. This is explained by the fact that, as a result of the capture of ${ }^{237} \mathrm{~Np}$ neutrons, ${ }^{238} \mathrm{Pu}$ and ${ }^{239} \mathrm{Pu}$ are formed, i.e., fissile materials that support the fission chain reaction for a long time. In addition, ${ }^{237} \mathrm{~Np}$ is characterized by a larger neutron-capture cross-section in the thermal region as compared to that of ${ }^{238} \mathrm{U}$, which leads to the efficient formation of fissile ${ }^{238} \mathrm{Pu}$ and ${ }^{239} \mathrm{Pu}$ isotopes. 


\section{Introducing protactinium into fuel compositions}

According to the neutron-physical characteristics, protactinium is close to neptunium: its capture cross-section in the thermal region is 202 barn (see Table 2). In the chain of nuclide transformations, they differ in daughter fissile nuclides (Fig. 3).

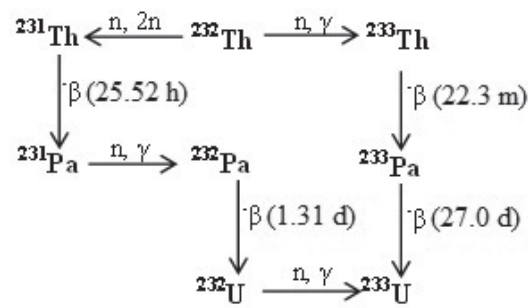

Figure 3. A chain of nuclide transformations starting with thorium (Bowman 2007).

Figure 4 shows the neutron multiplication factor in the process of fuel burnup containing protactinium.

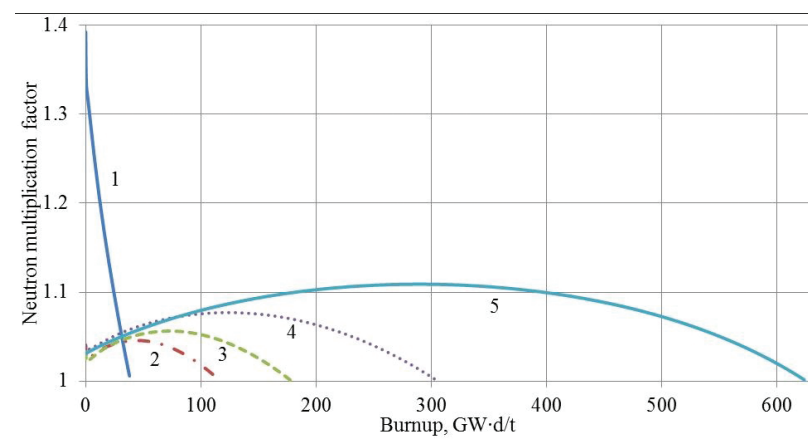

Figure 4. The effect of protactinium on the neutron multiplication factor in the process of fuel burning: 1) conventional uranium fuel $\left(4.4 \%\right.$ of ${ }^{235} \mathrm{U}+95.6 \%$ of $\left.{ }^{238} \mathrm{U}\right) ; 2$ ) fuel composition containing $11 \%$ of ${ }^{235} U+83 \%$ of ${ }^{238} U+6 \%{ }^{231} \mathrm{~Pa}$; 3 ) fuel composition containing $16 \%$ of ${ }^{235} \mathrm{U}+74 \%$ of ${ }^{238} \mathrm{U}+10 \%$ of ${ }^{231} \mathrm{~Pa}$; 4) fuel composition containing $26 \%$ of ${ }^{235} \mathrm{U}+54 \%$ of ${ }^{238} \mathrm{U}+20 \%$ of ${ }^{231} \mathrm{~Pa}$; 5) complete substitution of ${ }^{238} \mathrm{U}$ for ${ }^{231} \mathrm{~Pa}$ $\left(44 \%\right.$ of ${ }^{235} \mathrm{U}+56 \%$ of $\left.{ }^{231} \mathrm{~Pa}\right)$.

As we can see in the figure, the introduction of protactinium in the fuel composition leads to a decreased initial reactivity margin and higher fuel burnup. If ${ }^{238} \mathrm{U}$ is completely substituted for ${ }^{231} \mathrm{~Pa}$ (fuel composition containing $44 \%$ of ${ }^{235} \mathrm{U}+56 \%$ of ${ }^{231} \mathrm{~Pa}$ ), burnup reaches $624 \mathrm{GW} \cdot \mathrm{d} / \mathrm{t}$, while the neutron multiplication factor remains practically unchanged throughout the campaign and is small. For a VVER-1000 reactor, this campaign lasts about 40 years.

These results are explained by the following two circumstances. First, the capture of ${ }^{231} \mathrm{~Pa}$ neutrons leads to the sequential formation of moderately fissile ${ }^{232} \mathrm{U}$ and well-fissile ${ }^{233} \mathrm{U}$, which support the fission chain reaction. Second, ${ }^{231} \mathrm{~Pa}$ is characterized by a larger neutron-capture cross-section in the thermal region as compared to that of
${ }^{238} \mathrm{U}$, which leads to the efficient formation of fissile ${ }^{232} \mathrm{U}$ and ${ }^{233} \mathrm{U}$ nuclides.

\section{Reactivity coefficients of fuel containing protactinium and neptunium}

Reactivity control plays an important role in ensuring the safety of nuclear reactors (Safety of Nuclear Power Reactors). Let us consider the reactivity coefficients in the fuel and coolant temperatures for the case of fuel compositions doped by protactinium and neptunium. Compared to the initial value, the temperature of the reactivity coefficient increased by $100 \mathrm{~K}$ when it was estimated with regard to the fuel temperature and by $47 \mathrm{~K}$ when it was estimated with regard to the coolant temperature. Since the calculations consider the unit cell of a VVER-1000 reactor, the reactivity is determined through the infinite neutron multiplication factor $\left(k_{\infty}\right)$ instead of the effective neutron multiplication factor $\left(k_{\text {eff }}\right)$, which is a certain assumption (Bekurtz and Wirtz 1968, Bell and Glasstone 1970, Thomas and Belle 2019). The coolant properties were determined using the Water Steam Pro software package (Calculator: Water Steam Pro).

Changes in the fuel temperature coefficient of reactivity during the campaign of fuel campaign containing $44 \%$ of ${ }^{235} \mathrm{U}+56 \%$ of ${ }^{231} \mathrm{~Pa}$ are shown in Fig. 5 .

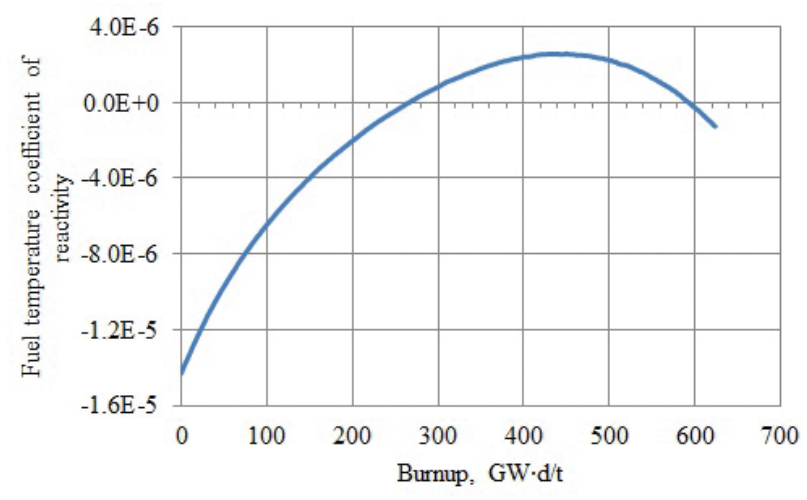

Figure 5. Changes in the fuel temperature coefficient of reactivity during the campaign of fuel containing $44 \%$ of ${ }^{235} \mathrm{U}+56 \%$ of ${ }^{231} \mathrm{~Pa}$.

Negative fuel temperature coefficients of reactivity are favorable because they make the reactor self-regulating. As we can see in the figure, the fuel temperature coefficient of reactivity for the fuel composition containing $44 \%$ of ${ }^{235} \mathrm{U}+56 \%$ of ${ }^{231} \mathrm{~Pa}$ at a certain point of the campaign takes a positive value. This does not meet safety the requirements. Before burnup reaches $266 \mathrm{GW} \cdot \mathrm{d} / \mathrm{t}(\sim 18$ years for a VVER-1000 reactor), the fuel temperature reactivity coefficient remains negative, and then it becomes positive until burnup reaches $592 \mathrm{GW} \cdot \mathrm{d} / \mathrm{t}(\sim 39$ years for a VVER-1000 reactor), then it decreases and again remains negative until the end of the campaign. 
Thus, it is necessary to determine a fuel composition containing protactinium which will be characterized by a negative fuel temperature coefficient of reactivity throughout the campaign. By means of calculation, it was found that the fuel composition containing $16 \%$ of ${ }^{235} \mathrm{U}+74 \%$ of ${ }^{238} \mathrm{U}+10 \%$ of ${ }^{231} \mathrm{~Pa}$ is characterized by negative reactivity coefficients in the fuel and coolant temperatures throughout the campaign (Fig. 6).

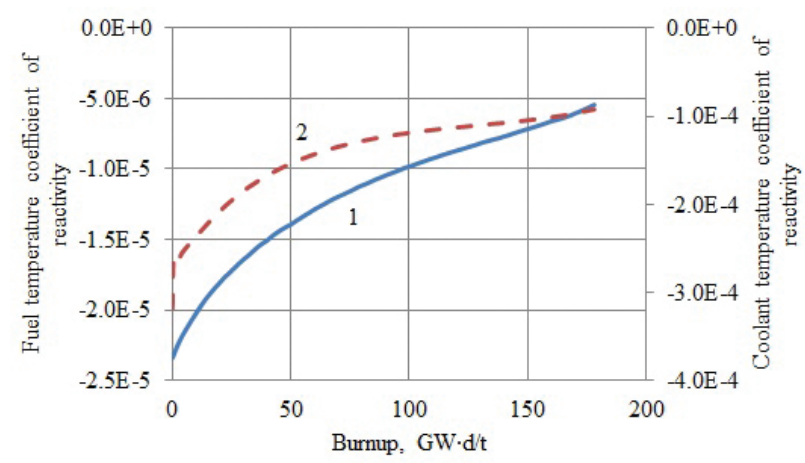

Figure 6. Changes in the reactivity coefficients for the fuel composition containing $16 \%$ of ${ }^{235} \mathrm{U}+74 \%$ of ${ }^{238} \mathrm{U}+10 \%$ of ${ }^{231} \mathrm{~Pa}$ during the campaign: 1) fuel temperature coefficient of reactivity; 2) coolant temperature coefficient of reactivity.

As we can see in the figure, the fuel composition containing $16 \%$ of ${ }^{235} \mathrm{U}+74 \%$ of ${ }^{238} \mathrm{U}+10 \%$ of ${ }^{231} \mathrm{~Pa}$ has a negative fuel temperature coefficient of reactivity throughout the campaign and is characterized by burnup of $178 \mathrm{GW} \cdot \mathrm{d} / \mathrm{t}$. The coolant temperature coefficient of reactivity for the fuel composition containing $16 \%$ of ${ }^{235} \mathrm{U}+74 \%$ of ${ }^{238} \mathrm{U}+10 \%$ of ${ }^{231} \mathrm{~Pa}$ also remains negative throughout the campaign. Thus, the safety requirements put a limit on the maximum protactinium content, making it impossible to achieve ultra-high burnup, as shown in the previous section of this paper. At the same time, burnup at the level of $178 \mathrm{GW} \cdot \mathrm{d} / \mathrm{t}$ is several times higher than the value characterizing conventional uranium fuel.

Let us consider the reactivity coefficients for the fuel composition containing neptunium $\left(35 \%\right.$ of ${ }^{235} \mathrm{U}+65 \%$ of ${ }^{237} \mathrm{~Np}$ ). The fuel temperature coefficient of reactivity is negative, whereas the coolant temperature coefficient of reactivity takes positive values throughout the campaign, which does not meet the safety requirements (Fig. 7).

By means of calculation, it was found that the fuel composition containing $16 \%$ of ${ }^{235} \mathrm{U}+74 \%$ of ${ }^{238} \mathrm{U}+$ $10 \%$ of ${ }^{237} \mathrm{~Np}$ has negative reactivity coefficients in the fuel and coolant temperatures throughout the campaign (Fig. 8).

Thus, the safety requirements that provide negative values of reactivity coefficients throughout the entire fuel campaign, nullify the potential of neptunium in terms of increasing fuel burnup - the achievable value is 46 $\mathrm{GW} \cdot \mathrm{d} / \mathrm{t}$, which is comparable to conventional uranium fuel for VVER-1000 reactors.

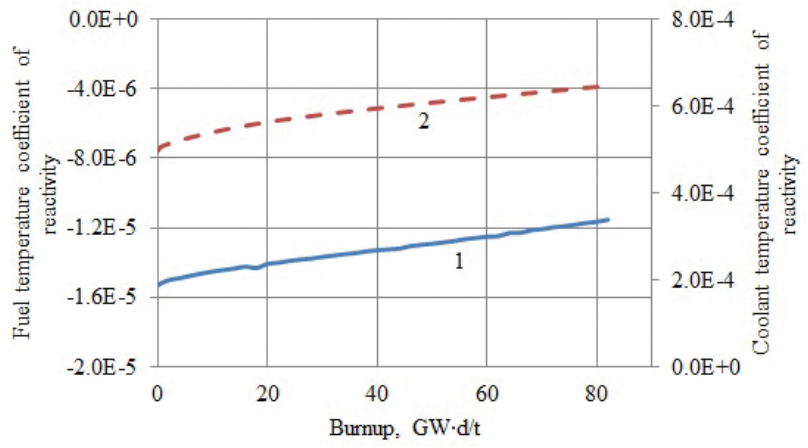

Figure 7. Changes in the reactivity coefficients forf the fuel composition containing $35 \%$ of ${ }^{235} \mathrm{U}+65 \%$ of ${ }^{237} \mathrm{~Np}$ during the campaign: 1) fuel temperature coefficient of reactivity; 2) coolant temperature coefficient of reactivity.

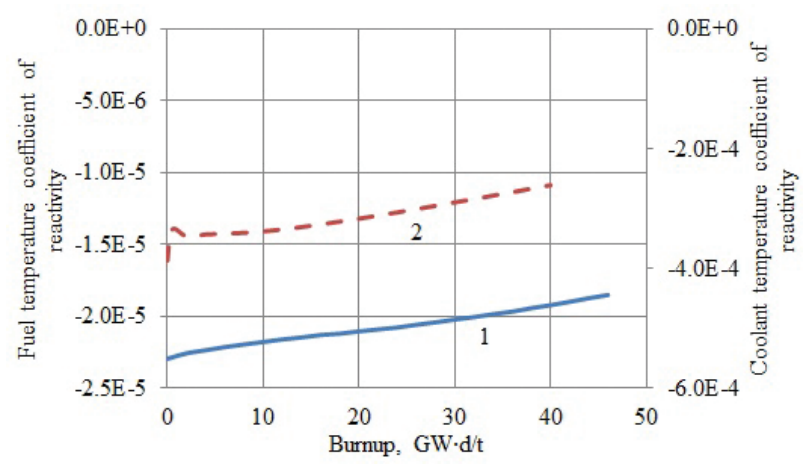

Figure 8. Changes in the reactivity coefficients for the fuel composition containing $16 \%$ of ${ }^{235} \mathrm{U}+74 \%$ of ${ }^{238} \mathrm{U}+10 \%$ of ${ }^{237} \mathrm{~Np}$ during the campaign: 1) fuel temperature coefficient of reactivity; 2) coolant temperature coefficient of reactivity.

\section{Availability of protactinium and neptunium for core loadings of high-power light-water reactors}

Currently, the IAEA estimates that spent nuclear fuel contains about 165 tons of neptunium worldwide (Status and Trends 2018). If we rely on the proposed fuel compositions with high neptunium contents, then these resources for loading a single VVER-1000 will be enough for only a few decades. Therefore, there is no question of large-scale nuclear power generation involving neptunium.

And since protactinium is practically absent in nature, the question arises of its production in significant quantities. There are two methods applicable for this purpose. The first method is to irradiate ${ }^{230} \mathrm{Th}$ available in uranium ores in power reactors. The disadvantage of this method is the low content of ${ }^{230} \mathrm{Th}$ in uranium ore only $16 \mathrm{~g} / \mathrm{t}$. At the current level of uranium production in the world (approximately $50,000 \mathrm{t} / \mathrm{y}$ ), this means that it is possible to produce less than a ton of protactinium per year; however, this option was successfully used in the USA in the 50s and $60 \mathrm{~s}$ of the $20^{\text {th }}$ century. 
The second method is to irradiate ${ }^{232} \mathrm{Th}$ with high-energy thermonuclear neutrons in a blanket of a hybrid thermonuclear reactor. The rate of protactinium production in the thorium blanket of such a reactor is about $1 \mathrm{~kg} / \mathrm{t} / \mathrm{y}$. The authors evaluated the possibility of producing protactinium in a thorium blanket surrounding an ITER thermonuclear reactor (thermonuclear power of $500 \mathrm{MW}$ ): it amounts up to $800 \mathrm{~kg}$ of protactinium per year.

In conclusion, it should be noted that, due to their limited reserves, the use of protactinium and neptunium will apparently be more attractive in small-scale power generation: at NPPs for remote areas, at floating NPPs or as a power sources in spaceships.

\section{Conclusions}

Fuel compositions containing protactinium and neptunium are characterized by increased burnup. In addition, protactinium is preferable to neptunium due to the best neutron-physical characteristics of ${ }^{232} \mathrm{U}$ and ${ }^{233} \mathrm{U}$ formed from protactinium as compared with the neutron-physical characteristics of ${ }^{238} \mathrm{Pu}$ and ${ }^{239} \mathrm{Pu}$ formed from neptunium.

The introduction of protactinium into fuel compositions ensures ultra-high burnup $(624 \mathrm{GW} \cdot \mathrm{d} / \mathrm{t})$ and a low neutron multiplication factor throughout the campaign; however, fuel with significant contents of protactinium is characterized by positive fuel temperature coefficients of reactivity.

The fuel composition containing $16 \%$ of ${ }^{235} \mathrm{U}+74 \%$ of ${ }^{238} \mathrm{U}+10 \%$ of ${ }^{231} \mathrm{~Pa}$ is characterized by negative reactivity coefficients for the fuel and coolant temperatures throughout the campaign. The achievable burnup value in this case is $178 \mathrm{GW} \cdot \mathrm{d} / \mathrm{t}$, and the campaign is $\sim 12$ years (for a VVER-1000 reactor). The production of protactinium is possible in hybrid fusion reactors (Krumbein et al. 1980; Kuteev and Khripunov 2009; Shmelev et al. 2015).

The introduction of neptunium into fuel compositions ensures high burnup $(82 \mathrm{GW} \cdot \mathrm{d} / \mathrm{t})$, but fuel with significant contents of neptunium is characterized by positive coolant temperature coefficients of reactivity.

To ensure negative reactivity coefficients throughout the campaign, the content of neptunium in the fuel must be reduced to such an extent that its potential to increase burnup is nullified, i.e., up to $46 \mathrm{GW} \cdot \mathrm{d} / \mathrm{t}$, which is comparable to conventional uranium fuel for VVER-1000 reactors.

\section{Acknowledgments}

The study was supported by Competitiveness Growth Program of the NRNU MEPhI.

\section{References}

- Babichev AP, Babushkina NA, Bratkovsky AM (1991) Physical Quantities. Handbook. Energoatomizdat Publ., Moscow, 1232 pp. [in Russian]

- Bekurtz K, Wirtz K (1968) Neutron Physics. Atomizdat Publ., Moscow, 456 pp. [in Russian]

- Bell D, Glasstone S (1970) Nuclear Reactor Theory. Van Nostrand Reinhold Company, 494 pp. http://lib.wwer.ru/fizika-yadernyh-reaktorov/ bell-teoriya-yader-reaktorov.zip [accessed Mar 10, 2019] [in Russian]

- Bowman SM (2007) Overview of the SCALE Code System. Nuclear Science and Engineering, American Nuclear Society, 97: 589-591.

- Calculator: Water Steam Pro (1999-2020) Calculator: Water Steam Pro. http://www.wsp.ru/en/ [accessed Mar 10, 2019]

- Gauld IC, Radulescu G, Ilas G, Murphy BD, Williams ML, Wiarda D (2011) Isotopic Depletion and Decay Methods and Analysis Capabilities in SCALE. Nuclear Technology, 174(2): 169-195. https:// doi.org/10.13182/NT11-3

- Klimov AN (1985) Nuclear Physics and Nuclear Reactors. Energoatomizdat Publ., Moscow, 325 pp. [in Russian]

- Krumbein A, Lemanska M, Segev M, Wagschal JJ, Yaari A (1980) Reaction Rate Calculations in Uranium and Thorium Blankets Surrounding a Central Deuterium-Tritium Neutron Source. Nuclear Technology, 48: 110-116. https://doi.org/10.13182/NT80-A32457

- Kulikov YeG, Kulikov GG, Kryuchkov EF, Shmelev AN (2013) Achievement of Higher Burn-up of LWR Fuel by Introduction of ${ }^{231} \mathrm{~Pa}$. Nuclear Physics and Engineering, 4(4): 291-299.

- Kuteev BV, Khripunov VI (2009) Modern Consideration of Hybrid Thermonuclear Reactor. VANT. Ser: Termoyadernyy Sintez, 1: 3-29. [in Russian]
- Maershin AA, Tsykanov VA, Golovanov VN (2001) Development and Tests of the Fast Reactor Fuel Elements with Vibropacked Oxide Fuel (VOF). Atomic Energy, 91(5): 378-385.

- Maslov VM, Baba M, Hasegawa A, Kornilov NV, Kagalenko AB, Tetereva NA (2004) Neutron Data Evaluation of ${ }^{231} \mathrm{~Pa}$. International Atomic Energy Agency, INDC(BLR)-019, 126 pp.

- Rearden BT, Jessee MA (2016) SCALE Code System. ORNL/TM2005/39, Version 6.2. prepared by Oak Ridge National Laboratory for the US Department of Energy, 2715 pp.

- Safety of Nuclear Power Reactors (2019) Safety of Nuclear Power Reactors, World Nuclear Association. http://www.world-nuclear. org/information-library/safety-and-security/safety-of-plants/safety-of-nuclear-power-reactors.aspx [accessed Mar 10, 2019]

- SCALE (2019) SCALE - A Comprehensive Modeling and Simulation Suite for Nuclear Safety Analysis and Design. http://scale.ornl.gov [accessed Mar 10, 2019]

- Shibata K, Iwamoto O, Nakagawa T, Iwamoto N, Ichihara A, Kunieda S, Chiba S, Furutaka K, Otuka N, Ohsawa T, Murata T, Matsunobu H, Zukeran A, Kamada S and Katakura J (2011) JENDL-4.0: A New Library for Nuclear Science and Engineering. Journal of Nuclear Science and Technology, 48(1): 1-30. https://doi.org/10.1080/ 18811248.2011.9711675

- Shmelev AN, Kulikov GG, Kulikov YeG, Apse VA (2016) Protactinium-231 as a new fissionable material for nuclear reactors that can produce nuclear fuel with stable neutron-multiplying properties. Kerntechnik, 81(1): 34-37. https://doi. org/10.3139/124.110598 
- Shmelev AN, Kulikov GG, Kurnaev VA, Salahutdinov GH, Kulikov YeG, Apse VA (2015) Hybrid fusion-fission reactor with a thorium blanket: Its potential in the fuel cycle of nuclear reactors. Physics of Atomic Nuclei, 78: 1100-1111. https://doi.org/10.1134/ S1063778815100117

- Soppera N, Bossant M, Dupont E (2014) JANIS 4: An Improved Version of the NEA Java-based Nuclear Data Information System. Nuclear Data Sheets, 120: 294-296. https://doi.org/10.1016/j. nds.2014.07.071
- Status and Trends in Spent Fuel and Radioactive Waste Management (2018) IAEA Nuclear Energy Series, 72 pp.

- Subrata B (2008) TIC Benchmark Analysis. Joint IAEA-ICTP Workshop on Nuclear Reaction Data for Advanced Reactor Technologies. Atomic Energy Regulatory Board of India, 19 pp. http://indico.ictp. it/event/a07153/session/60/contribution/34/material/0/0.pdf [accessed Mar 10, 2019]

- Thomas WK, Belle RU (2019) Dynamics and Control of Nuclear Reactors. Academic press, 402 pp. 